\title{
An International Network on Climate Change Impacts on Small Farmers in the Tropical Andes - Global Conventions from a Local Perspective
}

\author{
André Lindner ${ }^{1} \&$ Jürgen Pretzsch ${ }^{1}$ \\ ${ }^{1}$ Dresden University of Technology, Faculty of Environmental Sciences, Institute for International Forestry and \\ Forest Products, Tharandt, Germany \\ Correspondence: André Lindner, Dresden University of Technology, Faculty of Environmental Sciences, \\ Institute for International Forestry and Forest Products, Tharandt, Germany. Tel: 49-3520-3383-1832. E-mail: \\ andre.lindner@tu-dresden.de
}

Received: October 11, 2012 Accepted: December 20, 2012 Online Published: January 8, 2013

doi:10.5539/sar.v2n2p92

URL: http://dx.doi.org/10.5539/sar.v2n2p92

\begin{abstract}
The agricultural sector of Andean countries like Peru and Bolivia perceives the consequences of climate change in increasing water stress due to melting glaciers and changing precipitation patterns. Therefore mainly subsistence agricultural systems are increasingly vulnerable. Traditional inhabitants of the tropical Andean region are aware of the recurrent diversity of climate related impacts and its consequences, thus livelihood strategies are based on principles of risk management. Andean farmers are nowadays applying traditional strategies in a combination of homegrown experimentation and scientific know-how to cope with and adapt to a changing climate. Understanding these adaptations has become one of the most important aspects of research into climate change impacts and vulnerability. It provides essential knowledge for developing and transferring strategies towards a sustainable management in agriculture and agroforestry systems. But there still is a lack of a comparative assessment, especially in regions with high impact of extreme climate conditions. The endogenously determined strategies, which are based on the experience of the farmers, are to be complemented by knowledge and experiences coming from outside farm-household systems and communities. In a collaborative way, this exogenous knowledge is to be placed at the disposal of local actors. The necessary network approach leads to a comprehensive involvement of local stakeholders. Therefore a participative network on climate change may work as a tool to bridge the gap between the global discourse on climate change and local action.
\end{abstract}

Keywords: adaptation, agroforestry, livelihood strategies, research and development, sustainability, vulnerability

\section{Introduction}

Being the longest continental mountainous region in the world, the Andes are an about $7.000 \mathrm{~km}$ long continual range along the west coast of the South American subcontinent. They extend through seven countries including Peru and Bolivia. Here an international network of Peruvian, Bolivian and German partners was formed to investigate climate change impacts on small farmers (Figure 1). 


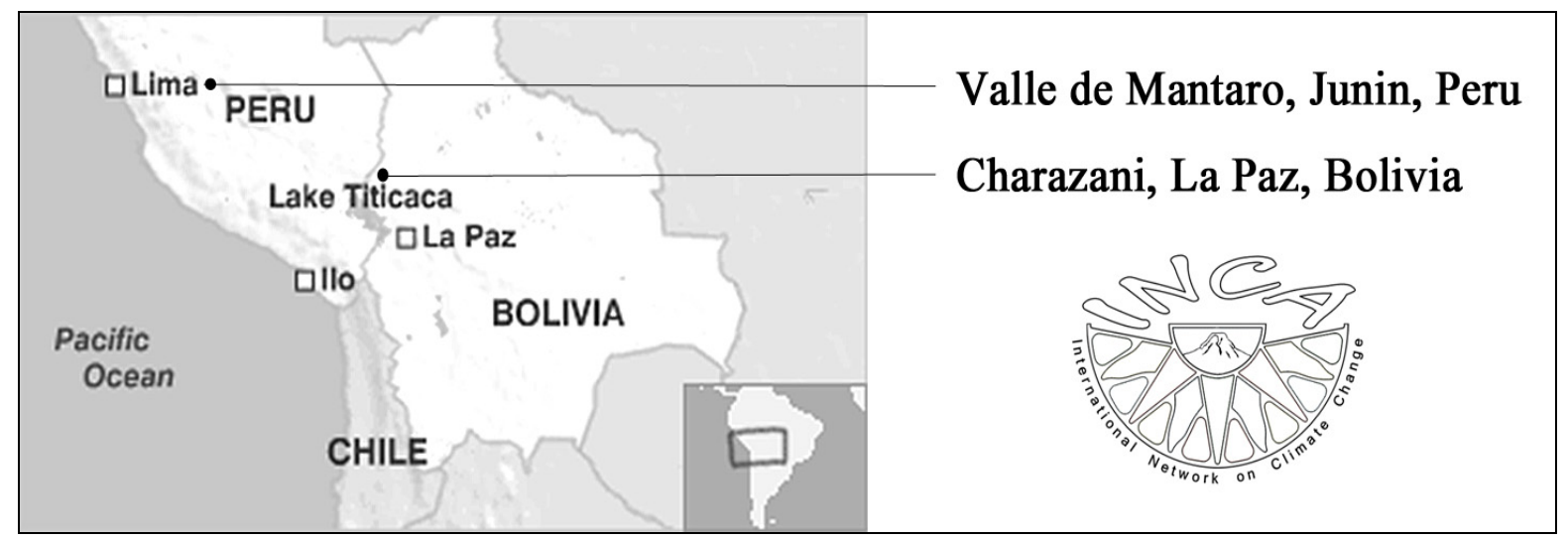

Figure 1. Current research sites of the International Network on Climate Change in the Andes of Peru and Bolivia

Despite the fact that climate change in high elevation tropical mountain ranges, like the Andes, is not well represented in recent General Circulation Models (GCM), local climate models show increased warming with a more distinct increase in temperature at higher elevations (Solman et al., 2008; Urrutia \& Vuille, 2009). The tropical Andes are characterized by the diversity of their ecosystems. Therefore the consequences of a changing climate are of increased concern, due to the effects that alterations within those ecosystems will have on human population, directly dependent on the services they provide (Vuille et al., 2008). Thus, for people living in the tropical Andes, climatic change is not a problem of the future - it's already there. Countries like Peru and Bolivia are already bearing the consequences of climate change, such as retreat of glaciers and extreme weather events, which are directly affecting crops, livestock, biodiversity, and, last but not least, increasing levels of poverty (Vuille et al., 2003). Almost the entire agricultural sector is mainly suffering from increasing water stress due to melting glaciers and changing precipitation patterns. The productivity, especially of small-scale subsistence oriented production systems is threatened, and thus the livelihood of smallholders is at risk (McDowell \& Hess, 2012).

As traditional inhabitants of the tropical Andean region, these farmers historically have had to cope with extreme daily temperatures, unpredictable weather events from one year to the next, and a diversity of environmental conditions scattered across the elevations. Therefore locals are aware of the recurrent diversity of climate related impacts and its consequences (Figure 2). Nonetheless climate change, functioning as an additional driver of ecosystem change and cause of shifts of resource use, brings another dimension. In the end the effects of a rapidly changing climate could jeopardize tropical Andean ecosystems and their capacity to provide ecosystem services (Anderson et al., 2011). Despite the climatic variability and the sometimes harsh conditions, the tropical Andean region is one of the first intensive agricultural societies in the world in which a manifold selection of crops was domesticated and adapted to high altitude environments and extreme climate fluctuations. Along with the availability of these crops, techniques were evolving to cope with such environmental constraints. Among those are complex agroforestry systems, agricultural terraces, artificial swamps, and raised fields (e.g. Erickson \& Candler, 1989; Lhomme \& Vacher, 2003). However, shifts in ecosystem services related to agricultural production could occur as a consequence of climate change and changing pattern of human settlement (Anderson et al., 2011). In the Andean region the permanent pressure to cope with shocks, and resource maximization, while diversification, linkage to markets and networking is a driver towards livelihood strategies, which are based on principles of risk management. This an essential point in contributing to the resilience of family livelihood development (Valdivia et al., 2010). Nowadays smallholders are applying these traditional strategies in a combination of homegrown experimentation and scientific know-how to adapt to climate change (Salick \& Ross, 2009). 


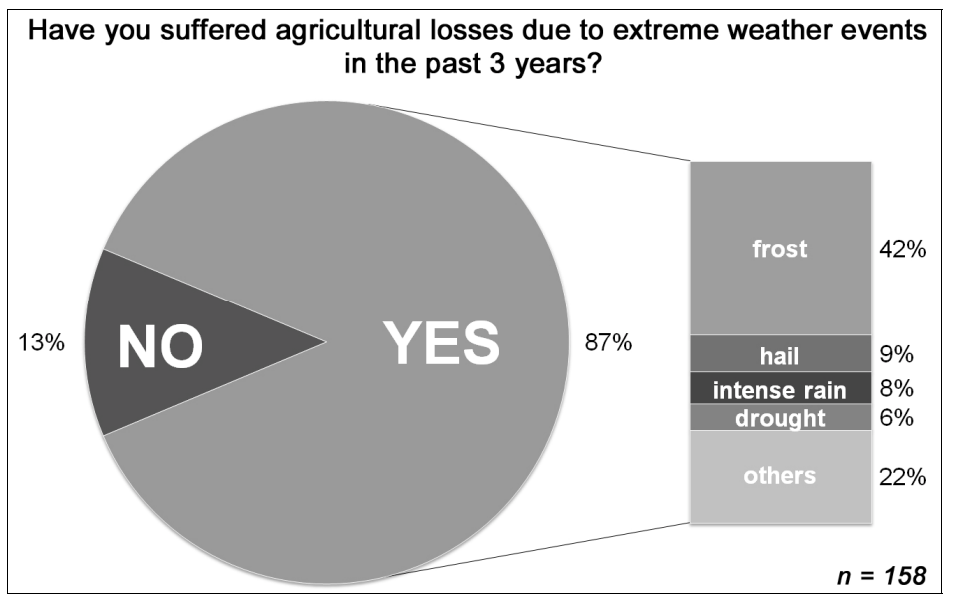

Figure 2. Responses out of 158 household interviews, conducted during a survey by the International Network on Climate Change in 2010 in the Achamayo watershed, Valle de Mantaro, Peru (Vidal-Merino et al., 2010 unpublished data)

Understanding these adaptations has become one of the most important focuses of research into climate change impacts and vulnerability, since it provides essential knowledge for developing and transferring strategies towards a sustainable management in agriculture and agroforestry (Pretzsch, 2005; Morton, 2007; Howden et al., 2007; Boomiraj et al., 2010). However, so far there still is a lack of information about the related local knowledge, behavior and action. Therefore a comparative assessment is needed, especially in regions with high impact of extreme climate conditions (Chhatre \& Agrawal, 2009). The endogenously determined strategies, which are based on the experience of the famers, are to be complemented by knowledge and experiences coming from outside farm-household systems and communities. In a collaborative way, this exogenous knowledge is to be placed at the disposal of local actors. Thus a participative network on climate change contributes to bridge the gap between the global discourse on climate change and local action. The necessary network approach leads to a far reaching involvement of the local actors.

\section{The Concept of an International Network on Climate Change}

The establishment of an International Network on Climate Change follows a nonlinear, interactive and iterative process. The main objective of the network is to understand the situation of local farming and forestry systems in the tropical Andes, deriving and testing livelihood strategies for small farms and indigenous communities together with local actors, scientists, experts, and students. Furthermore, the network contributes to transfer of technology and knowledge among all members.

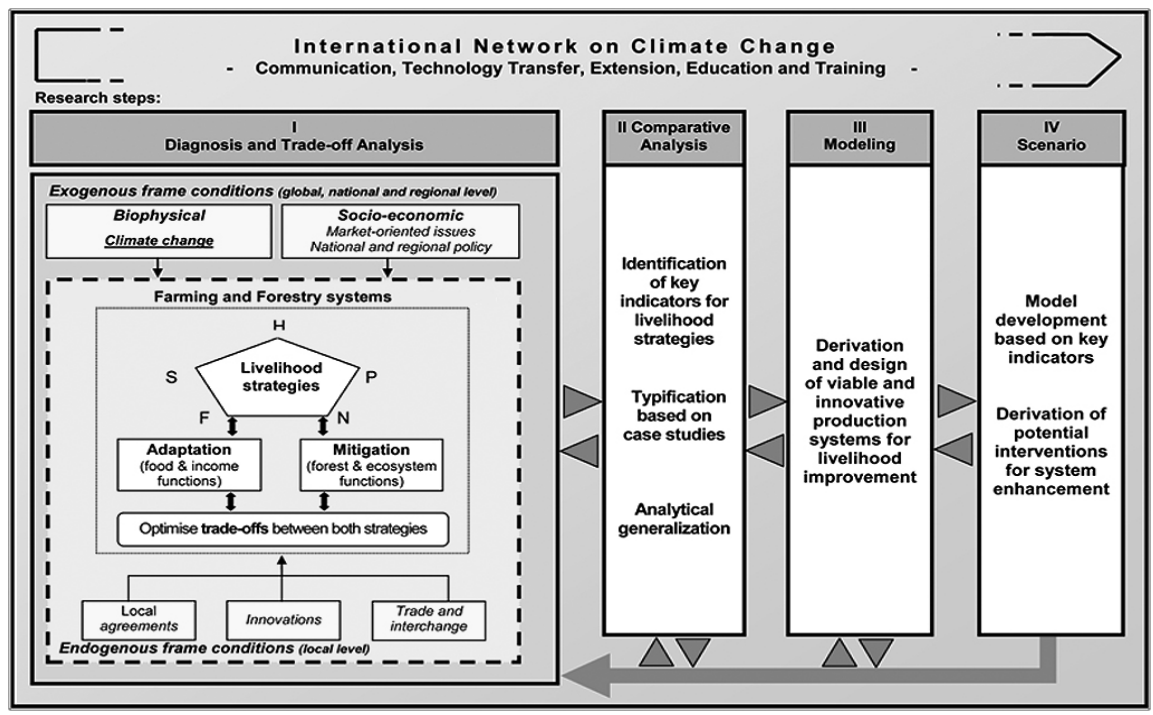

Figure 3. General framework and research steps of the International Network on Climate Change 
The specific objectives of the climate change network are:

i. To organize and integrate in a Research \& Development oriented network of relevant stakeholders on the topic of adaptation and mitigation on climate change in exemplary rural areas of the tropical Andes

ii. To conduct an analysis of the biophysical and socio-economic factors that influence livelihood strategies of traditional Andean farmers and to study how these systems are being affected by climate change

iii. To compare case study outcomes in order to generate and typify key indicators for livelihood strategies in the tropical Andean region and to comparatively assess trade-offs between the options that enhance food and income functions (adaptation strategies) and those options that enhance the ecosystem functions (mitigation strategies)

iv. To elaborate models for the simulation and planning of successful interventions in farming and forestry systems in order to improve adaptation and mitigation strategies

v. Scientific exchange of adaptation and mitigation strategies on climate change among local users, scientific community, state authorities, NGOs, as well as other relevant stakeholders in the tropical Andean region

vi. To contribute to the international debate within the UNFCCC (United Nations Framework, Convention on Climate Change) from the bottom up to consider the needs and experiences of local stakeholders in using natural resources

The network follows a Research \& Development (R \& D) approach, integrating case study based research, modeling, scenarios, extension and training. The profound understanding of the farming and forestry systems and the behavior of the local actors is a necessary precondition to identify subsequent R \& D network activities toward a local strategy for adaptation to and mitigation of climate change and its impacts.

The international network on climate change involves two strongly interrelated components: (1) communication, technology transfer education, training, which permits the involvement of all relevant actor groups in the stages from assessment to networking; (2) a participatory research and diagnosis process and modeling to cope with climate change effects. In this context an innovative element is the "social learning approach" (Rist et al., 2006), which is realized through socio-economic field laboratories. This approach combines a wide range of participative methods to be applied within the communities: a holistic diagnosis based on a rapid rural appraisal (Chambers, 1994) with focus on the resource status, the socio-economic and cultural conditions and on land-use practices; a subsequent joint analysis of strengths, weaknesses, opportunities and threats (SWOT) is conducted to evaluate the findings. At this juncture the main focus is put on the farming and forestry systems of local Andean people and their livelihood strategies to cope with climate change. To understand these strategies, the general performance of the farm will be assessed, including the knowledge of farmers and family members related to the ongoing production, production alternatives and their effects on climate change. The applied approach follows four main steps, as shown in Figure 3: The initial analytical steps are based in the classical Farming System Analysis and Research (Collinson, 2000), which has been further developed and applied to forestry systems. The interaction between the farming and forestry system analysis and the livelihood approach will permit the extraction and understanding of the vulnerability factors which determine living conditions and strategies of the affected farmers (Pretzsch, 2005). The livelihood approach is based on five forms of livelihood assets or types of capital: natural capital, social capital, financial capital, physical capital and human capital (e.g. Scoones, 1998; DFID, 1999). In a proximate comparative analysis key indicators of those capitals will be analyzed and trade-offs between different goals and production alternatives will be assessed. Experiences with trade-off analysis show that for a given set of resources and technology, obtaining more of a desirable outcome from a system, less from another desirable outcome (or more of an undesirable outcome) is required (Stoorvogel et al., 2004). Thus trade-offs imply a sacrifice or opportunity cost in terms of benefits foregone (Grimble \& Wellard, 1997). The portfolio of the farmer might shift between short term food security while taking in account a certain degree of degradation; medium term climate change adaptation with crop variation including agroforestry options; and the integration of trees or long term carbon storage with a focus on permanent cultures. The fourth and final step therefore focuses on the development of models and finally on the derivation of potential interventions for system enhancements.

In this regard agroforestry systems offer important opportunities for creating such synergies or desirable trade-offs. The promotion of agroforestry systems can contribute a reduction in the vulnerability of small-scale farmers and help them to adapt to climate change (Verchot et al., 2007). However, while there are hardly any complete win-win land uses concerning carbon storage and climate change mitigation (high carbon and high 
profit), there are certainly some options free of regret with medium to high profit and medium carbon stocks in cases of complex agro-forestry systems.

\section{The Outlook on an Endogenous Approach}

Furthermore, large parts of the Andean region are mainly inhabited by rural population dependent on subsistence agriculture and at the same time are areas with a social vulnerability that increases constantly due to degradation of the ecosystem caused by social and climatic change. There is an increasing vulnerability in terms of food security, which basically occurs as a result of the accumulation the small sized properties and a low level of economic diversification (Espinosa \& Bacerra, 2008). This situation made local authorities, governmental and nongovernmental organizations aware to take action and contribute to the improvement of quality of life in the region based on the traditional knowledge and local experience on resources management. New technologies and contemporary knowledge available have to be taken into account. In this regard Endogenous Sustainable Development is defined as the development from inside, taking cultural values as well as external knowledge in consideration (Molenaar, 2006). Additionally, endogenous development theory suggests that communities are more likely to remain cohesive and sustain their traditions, cultures, spirituality, and natural resources when they develop their future collectively and base their plans on the resources available within the community (Holly \& Harry, 2012). According to this baseline there is an unknown potential adaptive capacity that needs to be assed and to be linked directly to the culture and the environment. As every community is been affected in different way by climate change (Füssel, 2010) there is a need for site and situation specific stressor- and problem-assessment as exemplified in Table 1.

Table 1. Adaptive measures to environmental, economic and social stressors, identified in 30 household interviews (representing $25 \%$ of a total of 123 households in the community) and direct observations during a survey in Santa Rosa de Katta, Charazani, Bolivia (Vidaurre de la Riva, 2009 unpublished data)

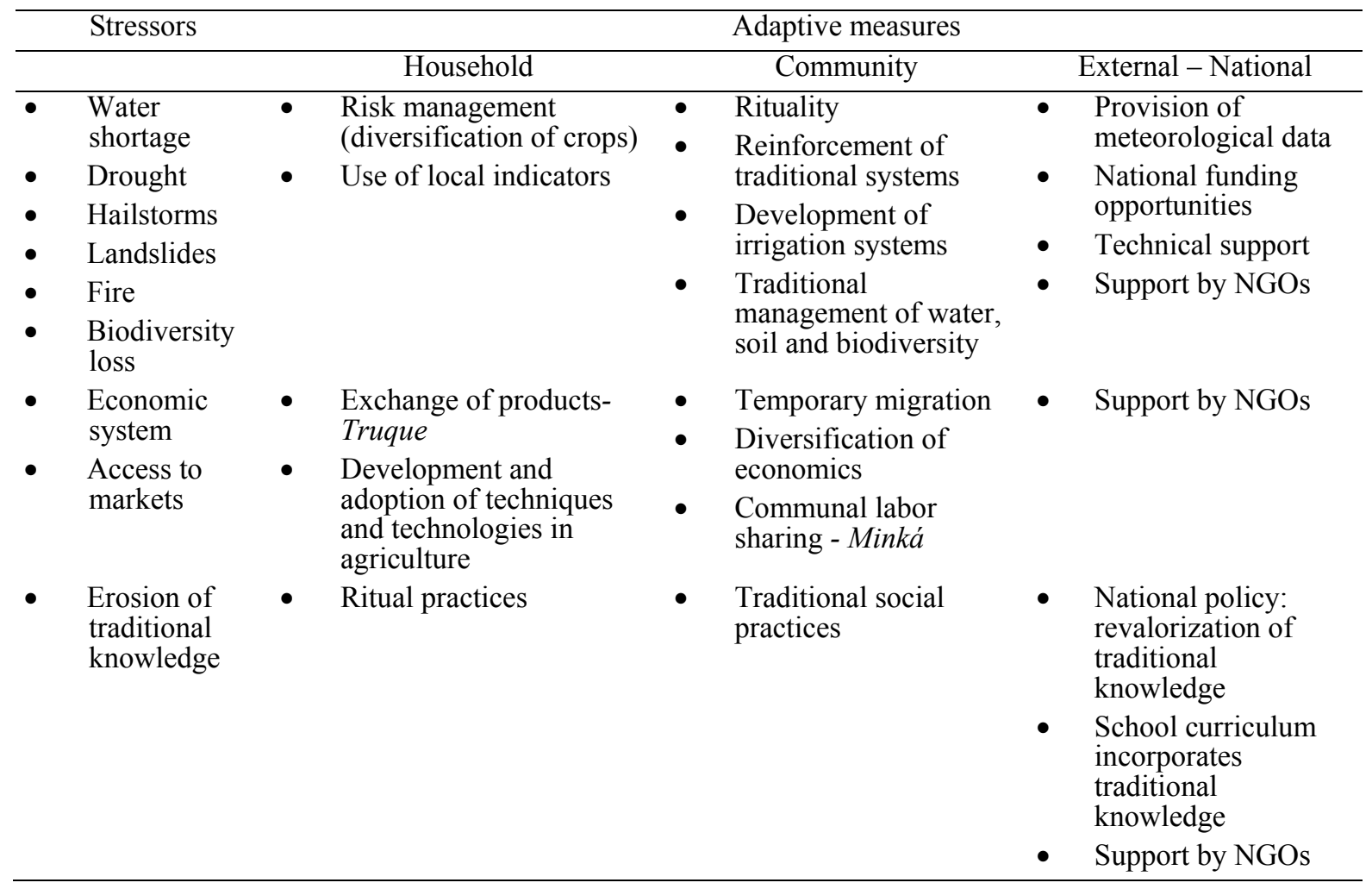

Indeed, the complexity of the situation challenges households and communities as well as governmental and non-governmental organizations to develop an adequate adaptive capacity along the Andes. Some recent international studies have highlighted the adaptation strategies and capacity that communities use to cope with climate change (e.g. Vuille et al., 2008; McDowell \& Hess, 2012; Nethononda et al., 2013). Nevertheless more efforts are needed to make use and learn from these examples and communicate the advantages and disadvantages of certain strategies and scenarios in the face of climate change. 
Therefore the targeted outcomes of the International Network on Climate Change are the establishment of transand interdisciplinary working groups on climate change to strengthen research capacities, the development of models to understand and predict the strategies of small farmers in the Andes to cope with a changing climate and academic education as well as extension actions at local community level.

Thus the main intention of the International Network on Climate Change is to understand the situation of local farming and forestry systems in the tropical Andes, deriving and testing livelihood strategies for small-scale farms and indigenous communities together with local actors, scientists, experts, and students. The network contributes to transfer of technology and knowledge among all members and bridges the gap between the global discourse on climate change and local action. The project concept introduced here might work as a model for similar approaches in different regions or as baseline for continuative initiatives.

\section{Acknowledgements}

We are grateful to the comments of three anonymous reviewers who helped to considerably improve an earlier version if the manuscript. The authors also wants to thank for the support and the provision of preliminary data sets by colleagues of the International Network on Climate Change, which is part of the climate networks initiative of the German Academic Exchange Service (DAAD), funded by the Federal Foreign Office of Germany.

\section{References}

Anderson, E. P., Marengo, J., Villalba, R., Halloy, S., Young, B., Cordero, D., ... Ruiz, D. (2011) Consequences of climate change for ecosystems and ecosystem services in the tropical Andes. In S. K. Herzog, R. Martínez, P. M. Jǿrgensen, \& H. Tiessen (Eds.), Climate change and biodiversity in the tropical Andes. Inter-American Institute for Global Change Research and Scientific Committee on Problems of the Environment .

Boomiraj, K., Wani Suhas, P., Garg Kaushal, K., Aggarwal, P. K., \& Palanisami, K. (2010). Climate change adaptation strategies for agro-ecosystem - a review. Agrometeorology, 12(2), 145-160.

Chambers R. (1994). The origins and practice of participatory rural appraisal. World Development, 22(7), 953-969. http://dx.doi.org/ 10.1016/0305-750X(94)90141-4

Chhatre, A., \& Agrawal, A. (2009). Trade-offs and synergies between carbon storage and livelihood benefits from forest commons. PNAS, 106(42), 17667-17670. http://dx.doi.org/10.1073/pnas.0905308106

Collinson, M. (2000). A history of farming system research. Food and Agriculture Organization of the United Nations (FAO) and CABI Publishing.

DFID. (1999). Sustainable livelihoods guidance sheets. DFID, London.

Espinosa, C., \& Bacerra, M. T. (2008). El cambio climatico no tiene fronteras - Impacto del Cambio Climático en la Comunidad Andina. Secretaría General de la Comunidad Andina. Lima, Peru.

Erickson, C. L., \& Candler, K. L. (1989). Raised fields and sustainable agriculture in the Lake Titicaca Basin of Peru. In J. O. Browder, (Ed.). Fragile lands of Latin America: Strategies for sustainable development. (pp. 230-248). Westview Press, Boulder, Co.

Füssel, H-M. (2007). Vulnerability: A generally applicable conceptual framework for climate change research. Global Environmental Change, 17(2), 155-167. http://dx.doi.org/10.1016/j.gloenvcha.2006.05.002

Grimble, R., \& Wellard, K. (1997). Stakeholder methodologies in natural resource management: A review of principles, contexts, experiences and opportunities. Agricultural Systems, 55, 173-193. http://dx.doi.org/10.1016/S0308-521X(97)00006-1

Holly, S., \& Harry, J. (2012). Biocultural Community Protocols: A Toolkit for Community Facilitators. Natural Justice: Cape Town.

Howden, S. M., Soussana, J. F., Tubiello, F. N., Chhetri, N., Dunlop, M., \& Meinke, H. (2007). Climate Change and Food Security Special Feature: Adapting agriculture to climate change. PNAS, 104(50), 19691-19696. http://dx.doi.org/10.1073/pnas.0701890104

Lhomme, J. P., \& Vacher, J. J. (2003). La mitigación de heladas en los camellones del altiplano andino. Bulletin de l'Institut Français d'Etudes Andines, 32(2), 377-399

McDowell, Julia Z., Hess, \& Jeremy, J. (2012). Accessing adaptation: Multiple stressors on livelihoods in the Bolivian highlands under a changing climate. Global Environmental Change, 22(2), 342-352. 
http://dx.doi.org/10.1016/j.gloenvcha2011.11.002

Molenaar, H. A. (2006). Communicating worldviews: Articulating global and local knowledge. In B. Haverkort, \& C. Reijntjes (Eds.), (pp. 117-135). Moving worldviews: Reshaping sciences, policies and practices for endogenous sustainable development. Compas, Leusden.

Nethononda, L. O., Odhiambo, J. J. O., \& Paterson, D. G. (2013). Indigenous knowledge of climatic conditions for sustainable crop production under resource-poor farming conditions using participatory techniques. Sustainable Agricultural Research, 2(1), 26-31. http://dx.doi.org/10.5539/sar.v2n1p26

Pretzsch, J. (2005). Forest related rural livelihood strategies in national and global development. Forests Trees and Livelihoods, 15(2), 115-127. http://dx.doi.org/10.1080/14728028.2005.9752515

Rist, S., Chiddambaranathan, M., Escobar, C., \& Wiesmann, U. (2006). It was hard to come to mutual understanding ... - The multidimensionality of social learning processes concerned with sustainable natural resource use in India, Africa and Latin America. Systematic Practice and Action Research, 19, 219-237. http://dx.doi.org/10.1007/s11213-006-9014-8

Salick, J., \& Ross, N. (2009). Traditional peoples and climate change. Global Environmental Change, 19(2), 137-139. http://dx.doi.org/10.1016/j.globenvcha.2009.01.004

Scoones, I. (1998). Sustainable rural livelihoods: a framework for analysis. IDS, Working Paper 72, IDS, Brighton, UK.

Solman, S., Nuñez, M., \& Cabré, M. F. (2008). Regional climate change experiments over southern South America. I: Present climate. Climate Dynamics, 30, 533-552. http://dx.doi.org/ 10.1007/s00382-007-0304-3

Stoorvogel, J. J., Antle, J. M., Crissman, C. C., \& Bowen, W. (2004). The tradeoff analysis model: integrated bio-physical and economic modeling of agricultural production systems. Agricultural Systems, 80(1), 43-66. http://dx.doi.org/10.1016/j.agsy.2003.06.002

Urrutia, R., \& Vuille, M. (2009). Climate change projections for the tropical Andes using a regional climate model: temperature and precipitation simulations for the end of the $21^{\text {st }}$ century. Journal of Geophysical Research, 114, D02108. http://dx.doi.org/ 10.1029/2008JD011021

Valdivia, C., Seth, A., Gilles, J. L., Garcia, M., Jimenez, E., Cusicanqui, J., ... Yucra, E. (2010). Adapting to Climate Change in Andean Ecosystems: Landscapes, Capitals, and Perceptions Shaping Rural Livelihood Strategies and Linking Knowledge Systems. Annals of the Association of American Geographers, 100(4), 818-834. http://dx.doi.org/10.1080/00045608.2010.500198

Verchot, L. V., Noordwijk, M., Kandji, S., Tomich, T., Ong, C., Albrecht, A., ... Palm, C. (2007). Climate change: linking adaptation and mitigation through agroforestry. Mitigation and Adaptation Strategies for Global Change, 12(5), 901-918. http://dx.doi.org/10.1007/s11027-007-9105-6

Vuille, M., Bradley, R. S., Werner, M., \& Keimig, F. (2003). 20th century climate change in the tropical Andes: Observations and model results. Climatic Change, 59, 75-99. http://dx.doi.org/10.1023/A:1024406427519

Vuille, M., Francou, B., Wagnon, P., Juen, I., Kaser, G., Mark, B. G., \& Bradley, R. S. (2008). Climate change and tropical Andean glaciers: Past, present and future. Earth-Science Reviews, 89, 79-96. http://dx.doi.org/10.1016/j.earscirev.2008.04.002 